Original Research Paper

\title{
On Expediency of the Preliminary Heat Treatment for Liquid-Phase Reduction of Waste Steelmaking Slag
}

\author{
${ }^{1}$ Evgeny Trofimov, ${ }^{1}$ Ilya Chumanov, ${ }^{1}$ Andrey Dildin and ${ }^{2}$ Olga Samoylova \\ ${ }^{1}$ Department of General Metallurgy, Faculty of Engineering and Technology, \\ South Ural State University, Zlatoust, Russian Federation \\ ${ }^{2}$ Department of Physical Chemistry, Faculty of Physical and Metallurgical, \\ South Ural State University, Chelyabinsk, Russian Federation
}

\author{
Article history \\ Received: 12-10-2015 \\ Revised: 24-11-2015 \\ Accepted: 25-11-2015 \\ Corresponding Author: \\ Evgeny Trofimov \\ Department of General \\ Metallurgy, Faculty of \\ Engineering and Technology, \\ South Ural State University, \\ Zlatoust, Russian Federation \\ Tel: $+7(3513) 665829$ \\ Email: splav.zlat@mail.ru
}

\begin{abstract}
The problem of using waste steelmaking slags as a technogenic source of metallurgical raw materials still has no sustainable solution and requires innovative ideas and approaches. The purpose of this paper is a theoretical and experimental study of the possibility and expediency of the preliminary heat treatment of steelmaking slags in a reducing medium for greater metal recovery. The subject of research is a slag sample taken from the slag heaps at Zlatoust Metallurgic Plant (the Russian Federation). To perform thermodynamic simulation of the processes running during heat treatment of a slag substance, the FactSage software package (version 6.4) was applied. For the ease of analysis the key calculation results are presented as a logarithmic dependence of component weights and composition of the considered phases on temperature. The experimental studies include heat treatment tests on slag samples at temperatures of 1100 and $1200^{\circ} \mathrm{C}$ in air and in the carbon monoxide medium with further separation of the derived product. The composition of test samples is determined by electron microprobe analysis and X-ray diffraction analysis. It has been reported that heat treatment in carbon monoxide medium makes possible to significantly increase the iron content in the derived magnetic fraction. The results of thermodynamic simulation, composition analysis of samples and weight data for the obtained magnetic fractions (resistant or non-resistant to the magnetic field) suggest that the preliminary heat treatment of slag in carbon monoxide medium is expedient.
\end{abstract}

Keywords: Thermodynamic Simulation, Experimental Study, Steelmaking Slag, Processing, High-Temperature Processes

\section{Introduction}

The research intended to study the composition and properties of ferrous slags (including steelmaking slags) and improve the technologies for their recycling and disposal is still relevant (Geiseler, 1996; Rao, 2004; Huiting et al., 2004; Durinck et al., 2008; Gudim et al., 2009; Huaiwei and Xin, 2011; Yildirim and Prezzi, 2011). Last but not least, the attention to slags is related to the environmental problems associated with their storage and disposal (Piatak et al., 2014). The conventional scope of application of waste steelmaking and blast-furnace slags is to manufacture building materials and articles made therefrom (Lun et al., 2008; Li et al., 2009; Nadeem and Pofale, 2012; Arribas et al.,
2015). Along with the conventional approaches the new areas of slag disposal are growing rapidly (Gahan et al., 2011; Mattila et al., 2014). However, the currently used plans, as a rule, provide only for a partial solution to a problem of slag heap disposal. The task of steelmaking slag recycling presents a particular difficulty (Das et al., 2007; Ma and Houser, 2014), first of all, due to the chemical complexity, i.e., a large number of various components and wide range of their concentrations.

The earlier studies showed that slag disposal may be arranged in such a way as to result in both building materials and metals, suitable for further refining and usage (Shen and Forssberg, 2003; Gladskikh et al., 2009; Menad et al., 2014). Waste steelmaking slag refining to extract metallic constituents should encompass the stage 
of high-temperature substance reduction. The most suitable reducing agent in this process is carbon. Under certain conditions the high-temperature liquid-phase metal reduction from steelmaking slags with carbon may be an essential process operation. It is apparent that the efficiency of reduction stage depends on temperature conditions and activity of slag components or admixtures (Gladskikh et al., 2011; Shakurov et al., 2014).

One of the key problems faced by the developers of slag refining technologies is the composition analysis and sequencing the processes of slag material preparation for high-temperature reduction. It is known that the weight ratio of reducible and irreducible slag components does not exceed $1 / 4$. Therefore, if the process of liquid-phase reduction is running with total volume of slag, its efficiency will be lower due to the following circumstances.

Firstly, the elevation of temperature of the slag and reducing agent mixture to the value of $1500^{\circ} \mathrm{C}$ and its maintaining during dozens of minutes requires significant excess power input.

Secondly, overrepresentation of irreducible oxides (calcium, aluminum, magnesium and silicon oxides) in the system prevents the reduced metal drops from flowing into the consolidated metallic phase. This effect becomes the most apparent as the thickness of the molten slag remarkably increases. This may lead to under-recovery of the reduced metal.

Therefore, it is desirable not to subject the entire volume of processed slag to the liquid-phase reduction, but a part thereof rich in iron (and other reducible metals). A part of slag poor in useful metals should be disposed without reduction treatment.

The slag can be divided into two such parts by magnetic separation (Alanyalı et al., 2006). However, it is known that not all iron compounds are highly sensitive to the magnetic action. So a material part of potentially reducible slag components may be lost.

The earlier studies of the process of extraction of iron and a number of alloying elements ( $\mathrm{Mn}, \mathrm{Cr}, \mathrm{V}$, Ti etc.) from the oxide component (Dildin et al., 2007; 2011; 2012) suggest that the process of solid-phase reduction of slag components may be essential before the liquidphase stage of the reduction process. The findings indicate that the preliminary solid-phase reduction (at temperature of $1100-1200^{\circ} \mathrm{C}$ ) may contribute to the greater metal extraction in the course of subsequent procedures. In tests described in (Dildin et al., 2007; 2011 ; 2012), graphite powder mixed with slag was used as a reducing agent for small-size slag. This approach is not recommended for industrial application as its implementation involves unnecessary graphite losses with a part of slag which will be refined during magnetic separation. It would be wiser to perform the preliminary reduction with a gaseous reducing agent, i.e., a gas mixture having predominant content of carbon monoxide. Thus, a by-product of liquid-phase reduction will be used (carbon monoxide is formed in large quantities in this process). Besides, there will be no problem of the reducing agent loss with a part of slag that cannot be processed by pyrometallurgical method.

However, it is known that carbon monoxide is a weaker reducing agent than carbon. The purpose of this paper is a theoretical and experimental study of the possibility and expediency of the preliminary heat treatment of steelmaking slags in a carbon monoxide medium for greater metal extraction.

\section{Materials and Methods}

For the purpose of thermodynamic simulation of high-temperature treatment of slag substance, the FactSage software complex (version 6.4) manufactured by Thermfact (Canada) and GTT Technologies (Germany) (Bale et al., 2002; 2009) was used.

The data on slag composition used as initial data in the process of simulation are presented in Table 1 . These data were obtained in the process of study (by the procedure described below) of the slag substance sample taken at Zlatoust Metallurgic Plant (Cheliabinsk Region, the Russian Federation), which was used for the experimental part. The results of Electron Microprobe Analysis (EMPA) for metals, silicon and sulfur are converted into weight ratio of oxides of these elements which are typical components of slag. The results of composition analysis are compared with the known data on the slag composition obtained from the earlier inhouse slag composition analysis as well as from literary sources. Some data on chemical and phase composition of these slags are specified in (Dildin et al., 2007). The presented material somewhat exceeds the specified concentration range by $\mathrm{Mn}, \mathrm{Cr}$ and $\mathrm{Si}$ content. We believe that it makes no principal difference for the purpose of this work.

Steelmaking slags inter alia contain a large quantity of calcium and magnesium oxides (as a rule in a combined form). Slag substance stays under conditions favorable to the formation of calcium and magnesium carbonates for a long time. The used slag substance contains a noticeable quantity of carbonates that is proved both by the EMPA findings and intentional tests performed to determine the volume of $\mathrm{CO}_{2}$, displaced by $\mathrm{HCl}$ solution, affecting the slag sample. According to the test data the initial slag sample contains approximately $6.3 \mathrm{~g} \mathrm{CO}_{2}$ per $100 \mathrm{~g}$.

Thermodynamic calculation was performed for $100 \mathrm{~g}$ of initial slag. The process simulation was performed for different composition of the gaseous phase. In the first case it was suggested that in addition to the slag the system should contain $20 \mathrm{~g}$ of oxygen under the pressure of $20,000 \mathrm{~Pa}$. Simulation of the stated conditions was performed within the temperature range of $0-1350^{\circ} \mathrm{C}$ in increments of $2^{\circ} \mathrm{C}$. 
Table 1. The content of slag used for the purpose of simulation

\begin{tabular}{lcl}
\hline Slag component & $\begin{array}{l}\text { Content of slag sample, } \\
\text { \% wt. }\left(\text { excl. } \mathrm{CO}_{2}\right)\end{array}$ & $\begin{array}{l}\text { Results of the earlier experimental studies. } \\
\text { \% wt. as reported (Dildin et al., 2007) }\end{array}$ \\
\hline $\mathrm{FeO}$ & 11.10 & $3.72-43.88$ \\
$\mathrm{MnO}$ & 1.39 & $2.1-5.0$ \\
$\mathrm{Cr}_{2} \mathrm{O}_{3}$ & 1.28 & $1.6-11.3$ \\
$\mathrm{TiO}_{2}$ & 0.56 & $0.23-2.75$ \\
$\mathrm{SiO}_{2}$ & 34.57 & $17.7-26.6$ \\
$\mathrm{CaO}$ & 29.18 & $21.9-47.4$ \\
$\mathrm{MgO}$ & 12.47 & $6.2-18.5$ \\
$\mathrm{Al} \mathrm{O}_{3}$ & 8.89 & $4.1-9.8$ \\
$\mathrm{SO}_{2}$ & 0.56 & $0.14-0.70$ \\
$\mathrm{Total}$ & 100.00 & \\
\hline
\end{tabular}

The second calculation showed the case where in addition to the slag the system contained $20 \mathrm{~g}$ of argon under the pressure of $100,000 \mathrm{~Pa}$. The calculation was performed within the temperature range of $850-1350^{\circ} \mathrm{C}$ in increments of $1^{\circ} \mathrm{C}$.

In the third and fourth cases it was suggested that in addition to the slag the system should contain $20 \mathrm{~g}$ of carbon monoxide under the pressure of $10,000 \mathrm{~Pa}$ and $100,000 \mathrm{~Pa}$, respectively. The temperature range in these cases was $900-1300^{\circ} \mathrm{C}$ in increments of $1^{\circ} \mathrm{C}$.

To simulate the thermodynamic data bases such as FSstel, FToxid, FactPS, embedded in FactSage 6.4, were used.

Variable composition phases (solid and liquid solutions) were selected from their total quantity in the course of preliminary simulation by excluding those variable composition phases which do not manifest themselves as existing ones. For clarity of results the FToxid-GARN phase was excluded from the list of variable composition phases.

A particular attention should be paid to the selection of oxide melt (from available in the FToxid database) used for simulation. For the first two calculations FToxid-SLAGB, i.e., Al, Ca, Fe(III), Mg, Mn(II), Si, Ti(III), Ti(IV) oxide and sulphate melts were used; for calculations with carbon monoxide (i.e., under reduction conditions) FToxid-SLAGA, i.e., Al, Ca, Cr(II), Cr(III), $\mathrm{Fe}(\mathrm{II}), \mathrm{Fe}(\mathrm{III}), \mathrm{Mg}, \mathrm{Mn}(\mathrm{II}), \mathrm{Mn}(\mathrm{III}), \mathrm{Si}, \mathrm{Ti}(\mathrm{III}), \mathrm{Ti}(\mathrm{IV})$ oxide and sulfide melts were used.

For the purpose of calculation we assumed the presence of all substances from the used databases in the system, except for duplicate ones (in the order of preference-FSstel, FToxid, FactPS) and those being the components of selected solutions (they were excluded automatically). In addition, $\mathrm{CaTiO}_{3}$ was excluded from the list of pure substances (as far as this substance is the base material of perovskite solution and it is not excluded from the list automatically).

The gas composition under specified conditions included all gaseous substances contained in the FactPS database for the given set of elements. We made allowance for deviation of the gaseous phase behavior from the perfect gas law.
Experimental studies included tests on the heat treatment of slag samples at the temperature of 1100 and $1200^{\circ} \mathrm{C}$ in air and in the carbon monoxide medium with further magnetic separation of the derived substance.

The slag substance taken from slag heaps at Zlatoust Metallurgic Plant was granulated to particle size less than $1 \mathrm{~mm}$. Upon that metallic beads (contained in the sample composition in a very small quantity) were removed. Thus, only the mineral part was subjected to further processing. The resulted powder was thoroughly mixed to average its composition. About 5 samples weighing $200 \mathrm{~g}$ each were taken from the granulated slag. The first sample was subjected to magnetic separation using a permanent magnet made of barium hexaferrite. Thus, two fractions were obtained: A magnetic and non-magnetic one, with their weight defined to a precision of $0.01 \mathrm{~g}$.

The second and third samples were heated in the resistance furnace, with the pieces of graphite placed inside (to create the CO-containing medium), up to the temperatures of 1100 and $1200^{\circ} \mathrm{C}$, respectively and retained under the stated temperature for $0.5 \mathrm{~h}$. Then the slag was taken from the furnace, cooled down, further granulated (to avoid the sintering impact on the results of magnetic separation) and divided into the magnetic and non-magnetic fractions. All obtained fractions were also weighted.

Finally, the fourth and fifth samples were subjected to the same treatment as used for the second and third samples, but without graphite pieces placed into the furnace operating medium.

The elemental qualitative and quantitative composition of each of 10 obtained fractions and the initial slag powder as well was determined by Electron Microprobe Analysis (EMPA) using the scanning electron microscope JEOL JSM-6460LV, equipped with the energy-dispersion spectrometer, manufactured by Oxford Instruments.

In the preparation for the composition analysis a small quantity of each fraction, selected by quartering, was thoroughly ground in the agate mortar to the consistent fine powder with a particle size of 
approximately $50 \mu \mathrm{m}$. The composition of derived powders was determined by EMPA in several fields of view with further averaging.

Along with the average composition analysis of slag samples with the scanning electron microscope, the qualitative and quantitative composition analysis was performed for some typical slag particles from different samples which were not refined.

To specify the changes in phase composition the initial slag and waste slag samples were subjected to the $\mathrm{X}$-ray diffraction analysis. The analysis was performed using the X-ray powder diffract meter Rigaku Ultima IV within the angular range of $10-90^{\circ} 2$ Theta with $\mathrm{Cu} \mathrm{K}$ alpha radiation.

\section{Results}

For the ease of analysis the key calculation results were presented as logarithmic dependences of component weighs and composition of considered phases on temperature, shown in Fig. 1-4.

Under different conditions the following various composition phases are formed (names of the respective phases according to the databases used for simulation are specified in brackets):
- Melilite (FToxid-Mel_) $-\mathrm{Ca}_{2}[\mathrm{Mg}, \quad \mathrm{Fe}(\mathrm{II}), \quad \mathrm{Fe}(\mathrm{III})$, $\mathrm{Al}]\left\{\mathrm{Al}, \mathrm{Fe}(\mathrm{III}), \mathrm{Si}_{2} \mathrm{O}_{7}\right.$

- Olivine (FToxid-OlivA)-(Ca, Fe, Mg, Mn) [Ca, Fe, $\mathrm{Mg}, \mathrm{Mn}] \mathrm{SiO}_{4}$

- Clinopyroxene (FToxid-cPyrA)-(Ca, Fe(II), Mg) [Mg, $\mathrm{Fe}(\mathrm{II}), \mathrm{Fe}(\mathrm{III}), \mathrm{Al}]\{\mathrm{Al}, \mathrm{Fe}(\mathrm{III}), \mathrm{Si}\} \mathrm{SiO}_{6}$

- Perovskite (FToxid-PERO)-solid solution of $\mathrm{Ca}_{2} \mathrm{Ti}_{2} \mathrm{O}_{6}-\mathrm{Ca}_{2} \mathrm{Ti}_{2} \mathrm{O}_{5}$

- Bixbyite (FToxid-Bixb)-a solid solution based on $\mathrm{Mn}_{2} \mathrm{O}_{3}$ containing small quantities of $\mathrm{Fe}_{2} \mathrm{O}_{3}, \mathrm{Cr}_{2} \mathrm{O}_{3}$ and $\mathrm{Al}_{2} \mathrm{O}_{3}$

- $\quad$ Spinel (FToxid-SPINA)-a solid solution with a cubic lattice, containing $\mathrm{Al}-\mathrm{Cr}-\mathrm{Fe}-\mathrm{Mg}-\mathrm{O}$ in this case, with a composition represented by the $\mathrm{AB}_{2} \mathrm{O}_{4}$ formula

- Oxide melt based on FToxid-SLAGB or FToxidSLAGA-in the first case this is the oxide-sulphate alloy and in the second case these are oxides with sulphide admixtures

- $\quad$ Sulphide melt (based on FToxid-SLAGA)

- FCC metallic (iron-based) phase (FSstel-FCC1)

- $\quad \mathrm{FeS}$ (FSstel-FES)-a solid solution (Fe, Mn)S

- gas and separate solid substances- $\mathrm{MnO}_{2}, \mathrm{CaSO}_{4}$, $\mathrm{Ca}_{3} \mathrm{Fe}_{2} \mathrm{Si}_{3} \mathrm{O}_{12}, \quad \mathrm{Ca}_{3} \mathrm{Al}_{2} \mathrm{Si}_{3} \mathrm{O}_{12}$ (in fact, last two substances are likely to form a solid solution)

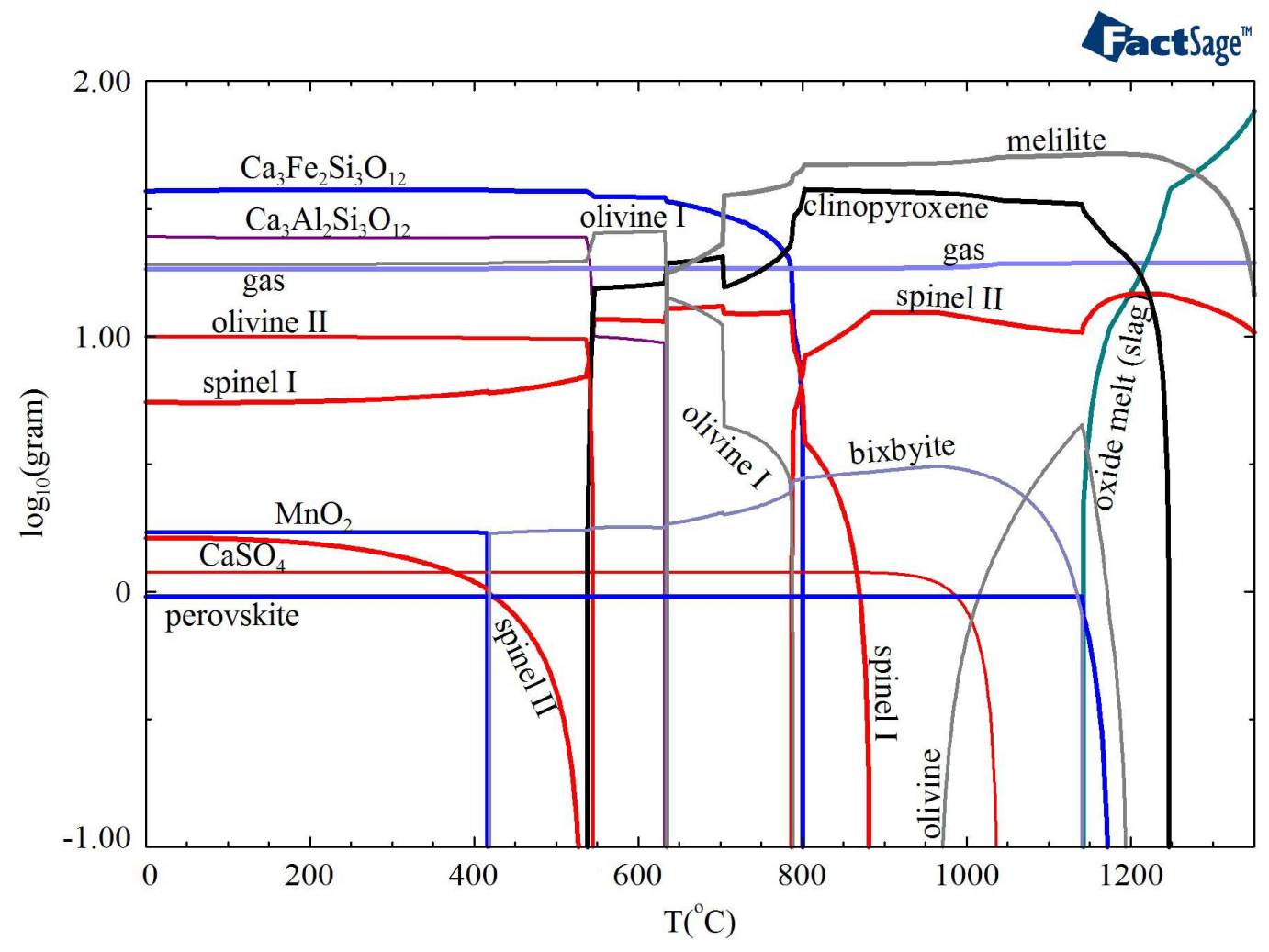

Fig. 1. Logarithmic dependence of phase weights on temperature with $20 \mathrm{~g}$ of gaseous oxygen for $100 \mathrm{~g}$ of slag under the system pressure of $20,000 \mathrm{~Pa}$ 


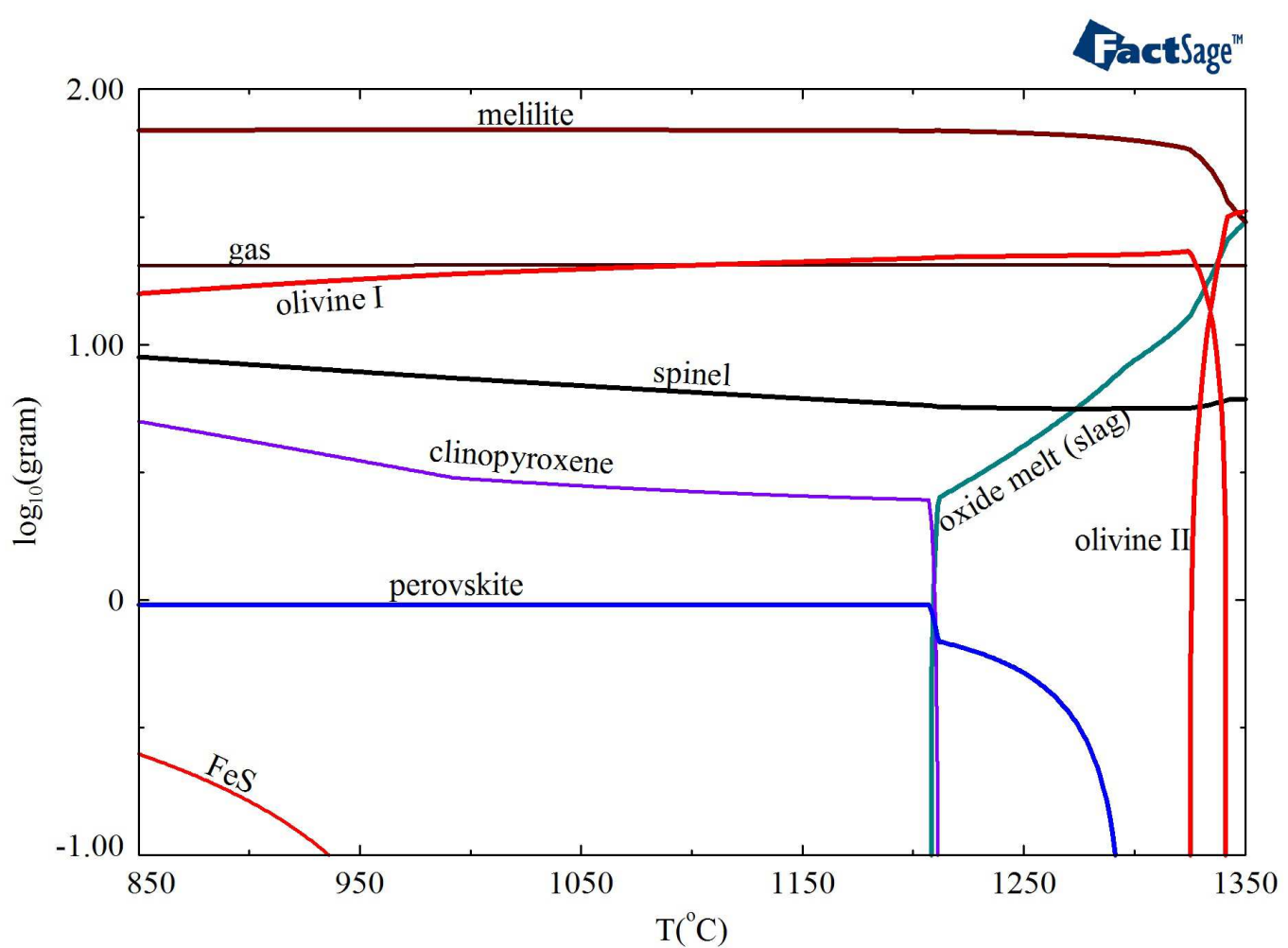

Fig. 2. Logarithmic dependence of phase weights on temperature with $20 \mathrm{~g}$ of gaseous argon for $100 \mathrm{~g}$ of slag under the system pressure of $100,000 \mathrm{~Pa}$

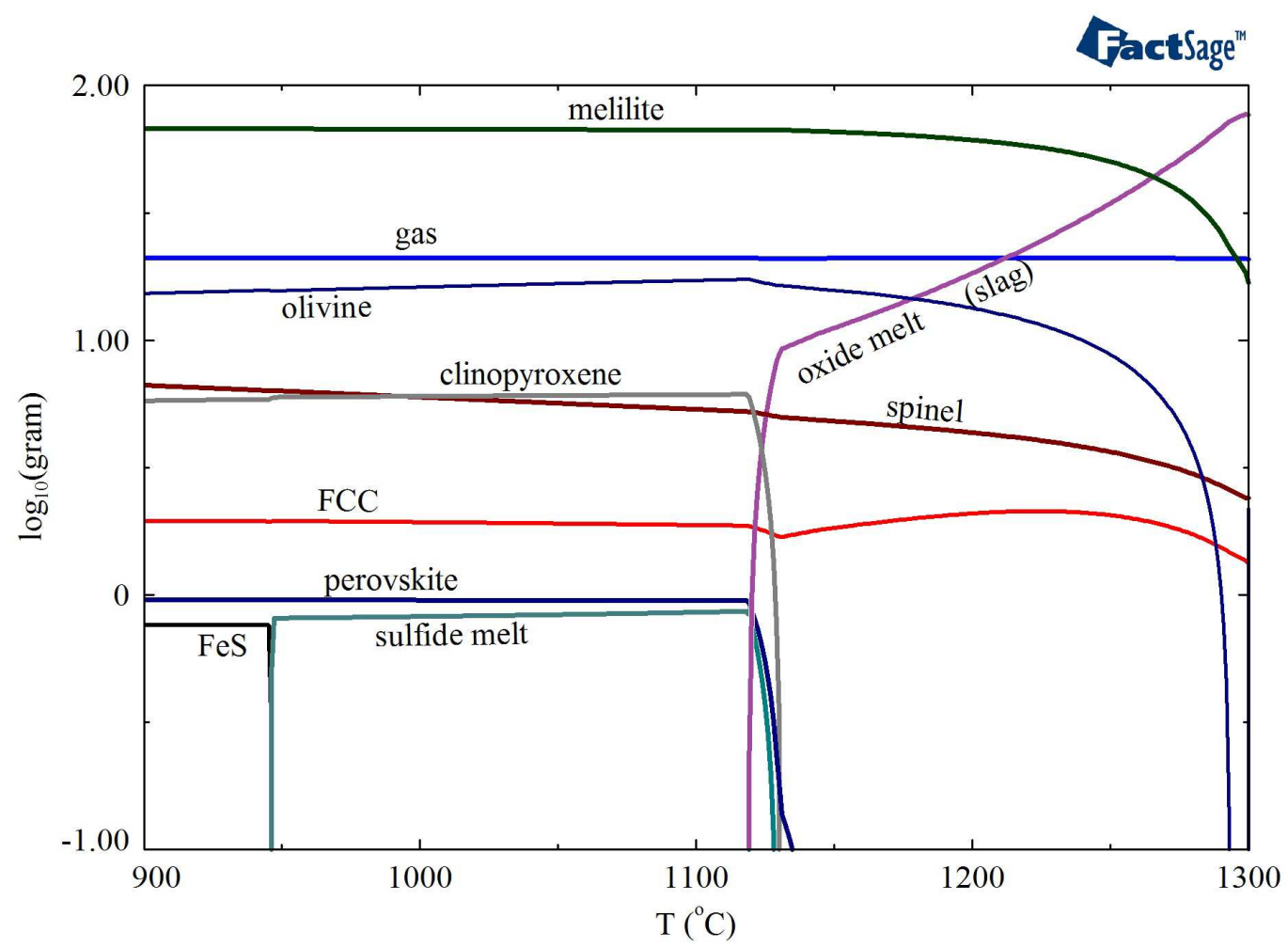

Fig. 3. Logarithmic dependence of phase weights on temperature with $20 \mathrm{~g}$ of gaseous CO for $100 \mathrm{~g}$ of slag under the system pressure of $10,000 \mathrm{~Pa}$ 


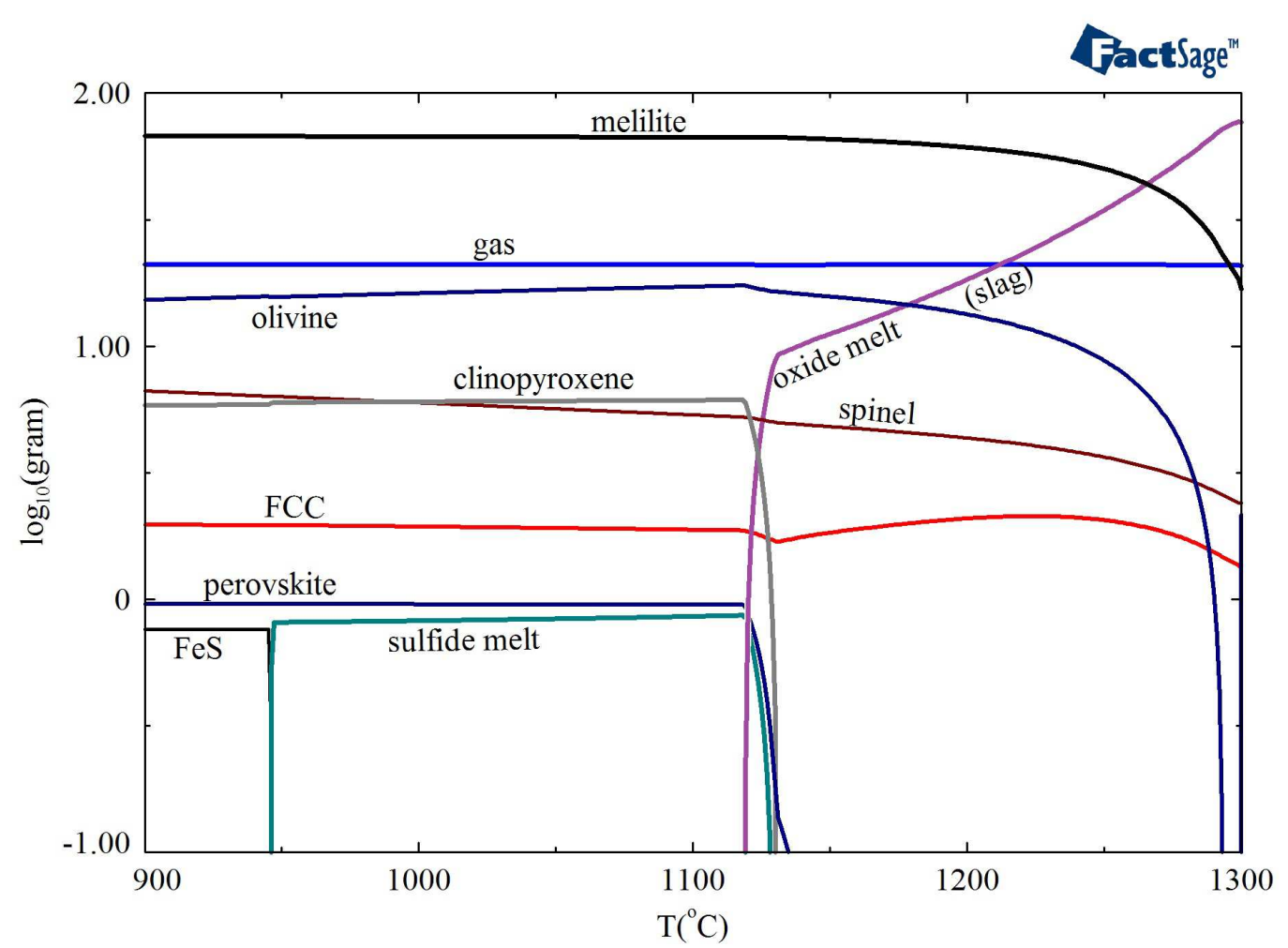

Fig. 4. Logarithmic dependence of phase weights on temperature with $20 \mathrm{~g}$ of gaseous CO for $100 \mathrm{~g}$ of slag under the system pressure of $100,000 \mathrm{~Pa}$

Table 2. The magnetic separation results

\begin{tabular}{lll}
\hline & $\begin{array}{l}\text { Magnetic fraction, } \\
\text { \% wt/sample No. }\end{array}$ & $\begin{array}{l}\text { Non-magnetic fraction, } \\
\text { \% wt/sample No. }\end{array}$ \\
\hline Initial slag (sample 1) & $48.4 /$ No. 2 & $51.6 /$ No. 3 \\
Slag treated in air at $1100^{\circ} \mathrm{C}$ & $76.0 /$ No. 4 & $24.0 /$ No. 5 \\
Slag treated in air at $1200^{\circ} \mathrm{C}$ & $71.5 /$ No. 6 & $28.5 /$ No. 7 \\
Slag treated in the reducible medium at $1100^{\circ} \mathrm{C}$ & $68.1 /$ No. 8 & $31.9 /$ No. 9 \\
Slag treated in the reducible medium at $1200^{\circ} \mathrm{C}$ & $71.9 /$ No. 10 & $28.1 /$ No. 11 \\
\hline
\end{tabular}

Table 3. Chemical composition (excluding oxygen and carbon) of slag samples based on the EMPA data (\% wt)

\begin{tabular}{lrlllllllr}
\hline Sample no. & \multicolumn{1}{c}{$\mathrm{Fe}$} & $\mathrm{Mn}$ & $\mathrm{Cr}$ & $\mathrm{Ti}$ & $\mathrm{Si}$ & $\mathrm{Ca}$ & $\mathrm{Mg}$ & $\mathrm{Al}$ & $\mathrm{S}$ \\
\hline No. 1 & 14.43 & 1.82 & 1.45 & 0.56 & 26.07 & 34.80 & 12.55 & 7.85 & 0.47 \\
No. 2 & 18.53 & 1.91 & 2.51 & 0.55 & 20.95 & 34.69 & 10.10 & 10.32 & 0.44 \\
No. 3 & 9.31 & 1.85 & 1.65 & 0.96 & 18.79 & 41.62 & 12.22 & 12.97 & 0.63 \\
No. 4 & 16.60 & 4.15 & 2.92 & 0.51 & 18.44 & 37.52 & 12.36 & 7.36 & 0.14 \\
No. 5 & 8.32 & 2.02 & 1.23 & 0.59 & 32.07 & 33.43 & 12.21 & 10.13 & 0.00 \\
No. 6 & 17.24 & 3.33 & 3.67 & 0.71 & 19.65 & 35.18 & 10.98 & 8.95 & 0.29 \\
No. 7 & 12.75 & 2.37 & 2.77 & 0.78 & 24.10 & 36.53 & 10.72 & 9.75 & 0.23 \\
No. 8 & 23.24 & 2.56 & 1.70 & 0.65 & 16.61 & 36.07 & 11.64 & 7.16 & 0.37 \\
No. 9 & 10.73 & 2.16 & 1.27 & 0.76 & 24.64 & 32.19 & 11.93 & 16.00 & 0.32 \\
No. 10 & 25.94 & 3.08 & 2.20 & 0.66 & 19.71 & 32.69 & 9.42 & 6.08 & 0.22 \\
No. 11 & 12.65 & 2.80 & 1.87 & 0.87 & 25.27 & 34.93 & 13.29 & 8.12 & 0.20 \\
\hline
\end{tabular}

Olivine and spinel form two phases of different composition within some temperature ranges.

The findings of experimental studies are presented in Table 2 and 3. Table 2 shows the results of magnetic separation (weight ratio of magnetic and non-magnetic fractions) for the initial slag and samples subject to heat treatment at temperatures of 1100 and $1200^{\circ} \mathrm{C}$ in the carbon monoxide medium and in air.

The results of composition analysis of slag samples processed by various methods are presented in Table 3. 
During the heat treatment carbonate content in the slag has decreased significantly (down to the value less than $1 \%$, as reflected by the volume of displaced $\mathrm{CO}_{2}$ ), though complete decomposition was not observed during the heat treatment or the samples partially re-absorbed $\mathrm{CO}_{2}$ from the air in the process of cool down of heat-treated samples and during their stay in air before the analysis. In order to avoid the impact of processes, related to carbonate decomposition and formation, on evaluation of the current metal reduction processes Table 3 presents slag compositions without reference to carbon and oxygen content of slag.

The results of the slag particle surface analysis treated in the other way show the expected diversity of chemical and phase composition.

Heat-treated magnetic fractions are marked by a large quantity of iron-containing oxide phase, which contains (based on relation of the number of atoms of oxygen and iron) both $\mathrm{Fe}^{+3}$ and $\mathrm{Fe}^{+2}$ (Fig. 5).

The particles of magnetic and non-magnetic fractions of the initial slag (Fig. 6 and 7) differ notably by a number of areas with elevated concentration of iron on their surface.

We observe quite small regions on the particle surface of magnetic fractions of slag, processed in air (Fig. 8), represented by substances containing ferric iron (based on a number of atoms of iron and oxygen).

Some results of the X-ray diffraction analysis of slag samples are presented in Fig. 9. However, the results of analysis of magnetic fractions of waste slag are of particular interest for us. Some peaks which are indicative of iron-containing phases are marked with figures.

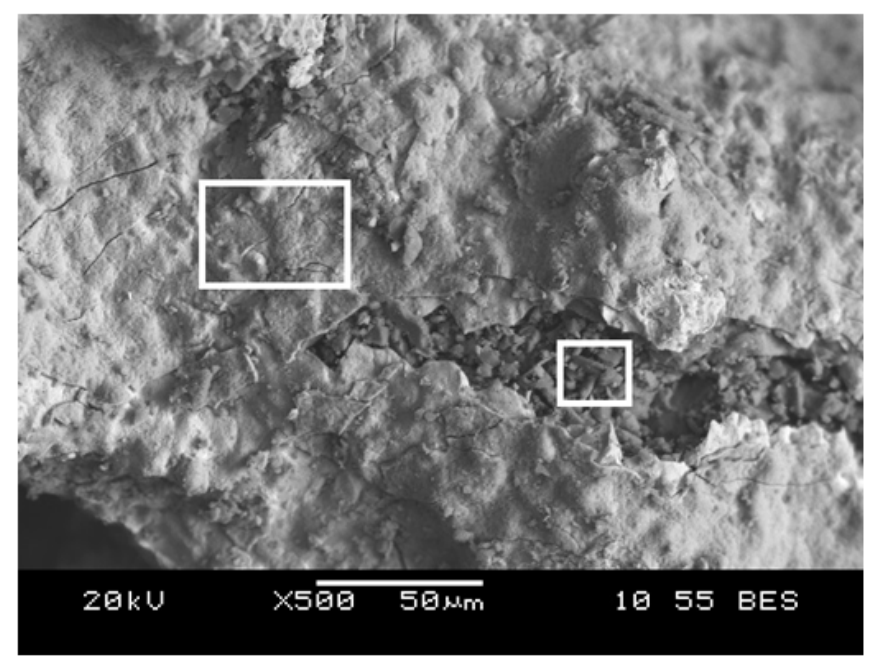

Fig. 5. The particle surface of the magnetic fraction of slag processed at $1200^{\circ} \mathrm{C}$ in the carbon monoxide medium (sample No. 10). The average surface composition in the region outlined with a large rectangular (\% at) is $41.33 \mathrm{Fe}, 1.37 \mathrm{Mg}, 0.72 \mathrm{Si}, 1.04 \mathrm{Ca}$, $55.54 \mathrm{O}$. The surface composition in the region outlined with a small rectangular (\% at) is $2.88 \mathrm{Fe}, 0.27 \mathrm{Mn}, 0.35 \mathrm{Cr}, 7.77$ $\mathrm{Mg}, 7.82 \mathrm{Si}, 1.25 \mathrm{Al}, 13,99 \mathrm{Ca}, 65.67 \mathrm{O}$

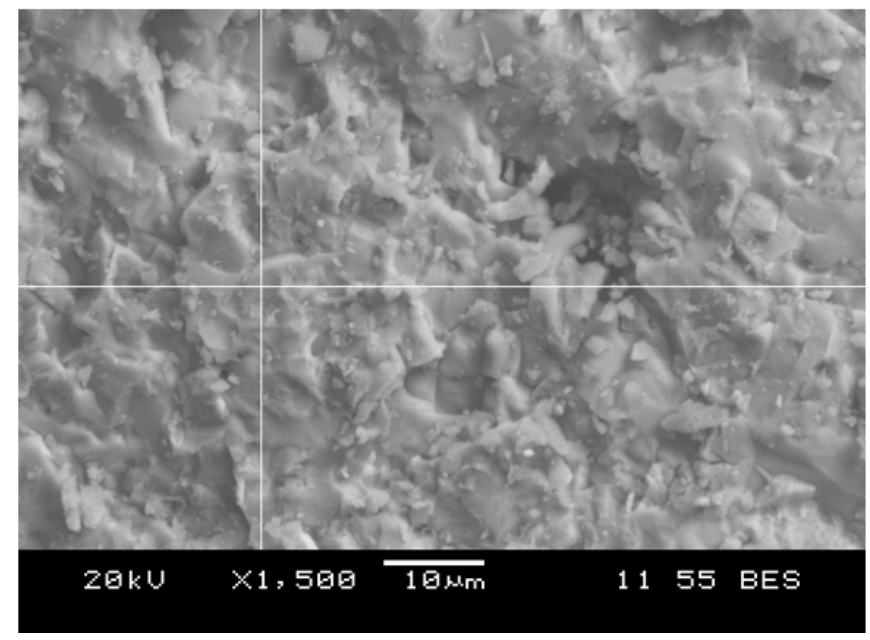

Fig. 6. The particle surface of the magnetic fraction of the initial slag (sample No. 2). The surface composition at the intersection of white lines (\% at) is $7.50 \mathrm{Fe}, 0.84 \mathrm{Mn}, 13.59 \mathrm{Si}, 2.58 \mathrm{Al}, 1.27 \mathrm{Mg} 18,72 \mathrm{Ca}, 55.49 \mathrm{O}$ 


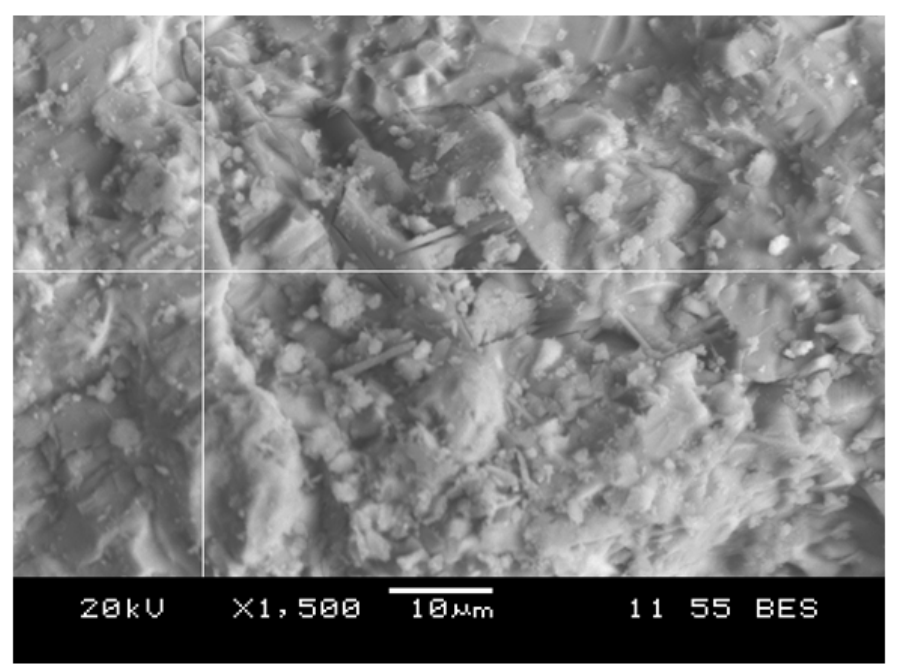

Fig. 7. The particle surface of the non-magnetic fraction of the initial slag (sample No. 3). The surface composition at intersection of white lines (\% at) is $0.25 \mathrm{Mn}, 14.32 \mathrm{Si}, 23,65 \mathrm{Ca}, 61.78 \mathrm{O}$

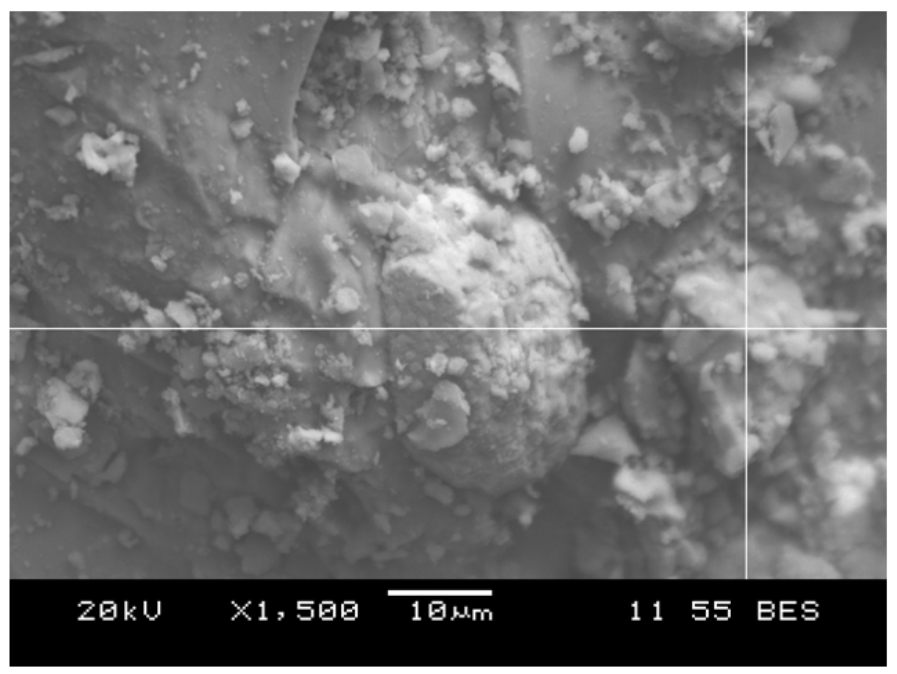

Fig. 8. The particle size of slag magnetic fraction processed at $1100^{\circ} \mathrm{C}$ in air (sample No. 4). The surface composition at the intersection of white lines (\% at) is $14.05 \mathrm{Fe}, 4.81 \mathrm{Mn}, 1.43 \mathrm{Si}, 0.65 \mathrm{Al}, 20.66 \mathrm{Mg}, 1.71 \mathrm{Ca}, 56.69 \mathrm{O}$

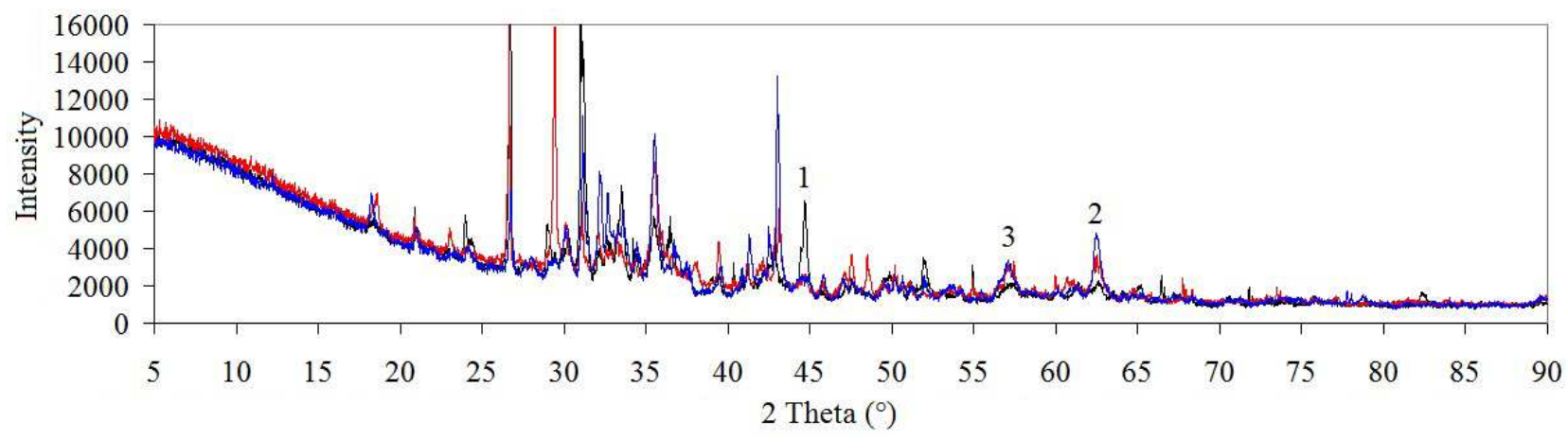

Fig. 9. The results of the X-ray diffraction analysis of samples 2 (red line), 4 (blue line) and 10 (black line). The peaks corresponding to metallic iron (1) and iron-containing spinel (2 and 3) are marked with figures 


\section{Discussion}

The peculiarities of the selected method of slag composition analysis had a specific impact on the results of experimental studies. Nevertheless, we can distinguish some main trends that are apparent from the given data:

- Magnetic separation for all cases, if applicable, leads to higher concentrations of iron, manganese and chrome in the magnetic fraction obtained

- Heat treatment of slag significantly increases the yield of the magnetic fraction both for the treatment in air and in carbon monoxide medium. The yield increase is almost the same for both mediums and it slightly depends on the treatment temperature $\left(1100\right.$ or $\left.1200^{\circ} \mathrm{C}\right)$

- Heat treatment in the carbon monoxide medium makes possible to significantly increase the iron content in the magnetic fraction obtained as well as in non-magnetic one. The latter is somehow related to the general decrease in slag weight in the process of heat treatment primarily due to carbonate decomposition (associated with loss of $\mathrm{CO}_{2}$ ) and loss of oxygen in the process of reduction

The data presented in Fig. 1 suggest the possible phase composition of the initial slag (low-temperature regions) and at the same time they contribute to a better understanding of the processes that occur to slag at high temperature treatment in air (in particular at the temperatures of 1100 and $1200^{\circ} \mathrm{C}$ ).

The results presented in Table 2 demonstrate that treatment at temperatures of 1100 and $1200^{\circ} \mathrm{C}$ allows increasing the magnetic fraction proportion in the slag significantly even without the reducing agent. This effect could be related to consolidation of particles due to sintering so that the magnetic components of consolidated particles enhance the penetration of nonmagnetic substance to the magnetic fraction. However, to avoid this, the substance was further disintegrated after heat treatment and the resulting particle size did not exceed in average the particle size of unprocessed slag.

At the same time the observed effect helps to explain the thermodynamic simulation data, according to which a significant transformation of slag phase composition takes place during heat treatment. The predominant phase at low temperatures, comprising only ferric iron $\left(\mathrm{Ca}_{3} \mathrm{Fe}_{2} \mathrm{Si}_{3} \mathrm{O}_{12}\right.$ in pure form or in a solid solution with the substances of this class) changes by phases containing both $\mathrm{Fe}^{+3}$ and $\mathrm{Fe}^{+2}$ (spinel, melilite and clinopyroxene). Perhaps, these processes result in a significant increase of the magnetic sensitivity of iron-containing slag components.

Such processes (differing quantitatively) apparently occur even in an inert medium (Fig. 2).

Partial reduction of multiple metals with carbon monoxide is expectedly supported by the thermodynamic simulation results (Fig. 3 and 4). According to these findings, a relatively small quantity of FCC iron-based solid solution is formed in the system. The data of X-ray diffraction analysis argues for this (Fig. 9). In addition to metallic iron reduction when slag inter-reacts with $\mathrm{CO}$, a partial reduction of iron from $\mathrm{Fe}^{+3}$ to $\mathrm{Fe}^{+}$will occur. The spinel formed in this process (with a substantial fraction presented by $\mathrm{Fe}_{3} \mathrm{O}_{4}$ ) is fixed both during the EMPA (Fig. 5) and X-ray diffraction analysis (Fig. 9).

These effects must also appear at a relatively low partial pressure of carbon monoxide, what can be seen by comparing Fig. 3 and 4 . The change in the system pressure (that will affect primarily the partial pressure of carbon monoxide) by 10 times, from 10,000 to 100,000 $\mathrm{Pa}$, has practically no effect on the phase equilibrium picture and on weights of the phases formed.

\section{Conclusion}

The use of carbon monoxide under simulation conditions cannot completely reduce the iron contained in the slag. However, if the refining process involves magnetic separation of slag followed by liquid-phase reduction of the magnetic fraction only, then carbon monoxide treatment could be useful at the first reduction stage as a solid-phase reduction at relatively low temperatures to increase the magnetic fraction yield in the magnetic separation process.

Consideration of sample composition analysis results, as well as the weight data for the obtained slag fractions (resistant and non-resistant to the magnetic field) allow for the conclusion that the preliminary heat treatment of slag in the carbon monoxide medium is expedient.

\section{Acknowledgment}

This research was executed with the financial support from the Ministry of Education and Science of the Russian Federation. A unique identifier of the applied research is RFMEFI57414X0090.

\section{Author's Contributions}

Evgeny Trofimov: Designed the research plan and organized the study, performed the thermodynamic modeling.

Ilya Chumanov: Contributed to the writing of the manuscript.

Andrey Dildin: Participated in all experiments and writing of the manuscript.

Olga Samoylova: Contributed to the thermodynamic modeling, performed the analysis of experimental data.

\section{Ethics}

The authors have no conflicts of interest in the development and publication of current research. 


\section{References}

Alanyalı, H., M. Cöl, M. Yılmaz and S. Karagoz, 2006. Application of magnetic separation to steelmaking slags for reclamation. Waste Manage., 26: 1133-1139. DOI: 10.1016/j.wasman.2006.01.017

Arribas, I., E. Ruiz, V. Ortega-López and J.M. Manso, 2015. Electric arc furnace slag and its use in hydraulic concrete. Construct. Building Mater., 90: 68-79. DOI: 10.1016/j.conbuildmat.2015.05.003

Bale, C.W., E. Bélisle, P. Chartrand, S.A. Decterov and G. Eriksson et al., 2009. FactSage thermochemical software and databases-recent developments. Calphad, 33: 295-311.

DOI: 10.1016/j.calphad.2008.09.009

Bale, C.W., P. Chartrand, S.A. Degterov, G. Eriksson and K. Hack et al., 2002. FactSage thermochemical software and databases. Calphad, 26: 189-228.

DOI: 10.1016/S0364-5916(02)00035-4

Das, B., S. Prakash, P.S.R. Reddy and V.N. Misra, 2007. An overview of utilization of slag and sludge from steel industries. Resources, Conservat. Recycl., 50: 40-57. DOI: 10.1016/j.resconrec.2006.05.008

Dildin, A.N., V.I. Chumanov and I.V. Chumanov, 2011. Systematic use of wastes in steel production. Metallurgist, 54: 737-739.

DOI: $10.1007 / \mathrm{s} 11015-011-9367-9$

Dildin, A.N., V.I. Chumanov and T.A. Bendera, 2007. Steelmaking slag utilization. Bulletin of the South Ural State University. Series Metallurgy, 13: 15-16.

Dildin, A.N., V.I. Chumanov, I.V. Chumanov and V.E. Eremyashev, 2012. Solid-phase reduction of waste products from steelmaking. Metallurgist, 56: 91-96. DOI: $10.1007 / \mathrm{s} 11015-012-9541-8$

Durinck, D., F. Engström, S. Arnout, J. Heulens and P.T. Jones et al., 2008. Hot stage processing of metallurgical slags. Resources, Conservat. Recycl., 52: $1121-1131$.

DOI: $10.1016 /$ j.resconrec.2008.07.001

Gahan, C.S., J.E. Sundkvist, F. Engström and Å. Sandström, 2011. Utilisation of steel slags as neutralising agents in biooxidation of a refractory gold concentrate and their influence on the subsequent cyanidation. Resources, Conservat. Recycl., 55: 541-547. DOI: 10.1016/j.resconrec.2011.01.005

Geiseler, J., 1996. Use of steelworks slag in Europe. Waste Manage., 16: 59-63. DOI: $10.1016 /$ S0956-053X(96)00070-0

Gladskikh, V.I., V.V. Naumkin, N.V. Sukinova and Z.N. Murzina, 2009. Deep processing of nonmagnetic metallurgical slags for complete iron extraction. Steel Translat., 39: 399-401.

DOI: $10.3103 / \mathrm{S} 0967091209050088$

Gladskikh, V.I., A.V. Bochkarev, N.V. Sukinova, Z.N. Murzina and I.P. Frolova, 2011. Improving slag processing at OAO MMK. Steel Translat., 41: 541-543. DOI: 10.3103/S0967091211060052
Gudim, Y.A., A.A. Golubev, S.G. Ovchinnikov and I.Y. Zinurov, 2009. Waste-free processing of steelsmelting slag. Steel Transl., 39: 612-614. DOI: $10.3103 / \mathrm{S} 0967091209070237$

Huaiwei, Z. and H. Xin, 2011. An overview for the utilization of wastes from stainless steel industries. Resources Conservat. Recycl., 55. 745-754. DOI: $10.1016 /$ j.resconrec.2011.03.005

Huiting, S., E. Forssberg and U. Nordström, 2004. Physicochemical and mineralogical properties of stainless steel slags oriented to metal recovery. Resources, Conservat. Recycl., 40: 245-271. DOI: 10.1016/S0921-3449(03)00072-7

Li, Y.F., Y. Yao and L. Wang, 2009. Recycling of industrial waste and performance of steel slag green concrete. J. Central South Univ. Technol., 16: 768-773. DOI: $10.1007 / \mathrm{s} 11771-009-0128-\mathrm{x}$

Lun, Y.X., M.K. Zhou, X. Cai and F. Xu, 2008. Methods for improving volume stability of steel slag as fine aggregate. J. Wuhan Univ. Technol., 23: 737-742. DOI: $10.1007 / \mathrm{s} 11595-007-5737-3$

Ma, N. and J.B. Houser, 2014. Recycling of steelmaking slag fines by weak magnetic separation coupled with selective particle size screening. J. Cleaner Product., 82: 221-231. DOI: 10.1016/j.jclepro.2014.06.092

Mattila, H.P., H. Hudd and R. Zevenhoven, 2014. Cradle-to-gate life cycle assessment of precipitated calcium carbonate production from steel converter slag. J. Cleaner Product., 84: 611-618.

DOI: $10.1016 /$ j.jclepro.2014.05.064

Menad, N., N. Kanari and M. Save, 2014. Recovery of high grade iron compounds from LD slag by enhanced magnetic separation techniques. Int. J. Mineral Process., 126: 1-9.

DOI: $10.1016 /$ j.minpro.2013.11.001

Nadeem, M. and A.D. Pofale, 2012. Utilization of industrial waste slag as aggregate in concrete applications by adopting taguchi's approach for optimization. Open J. Civil Eng., 2: 96-105. DOI: $10.4236 /$ ojce.2012.23015

Piatak, N.M., M.B. Parsons and R.R. Seal, 2014. Characteristics and environmental aspects of slag: A review. Applied Geochem., 57: 236-266. DOI: 10.1016/j.apgeochem.2014.04.009

Rao, S.R.R., 2004. Resource recovery and recycling from metallurgical wastes. Waste Manage. Series, 7: 1-581. DOI: 10.1016/S0713-2743(06)80097-8

Shakurov, A.G., V.V. Zhuravlev, V.M. Parshin, Y.S. Shkol'nik and A.D. Chertov, 2014. Processing of liquid steelmaking slags to obtain commercial products. Steel Translat., 44: 166-172. DOI: $10.3103 / \mathrm{S} 0967091214020193$

Shen, H. and E. Forssberg, 2003. An overview of recovery of metals from slags. Waste Manage., 23: 933-949. DOI: 10.1016/S0956-053X(02)00164-2

Yildirim, I. Z. and M. Prezzi, 2011. Chemical, mineralogical and morphological properties of steel slag. Adv. Civil Eng., DOI: 10.1155/2011/463638 